Check for updates

Cite this: RSC Adv., 2018, 8, 36927

Received 20th August 2018 Accepted 25th October 2018

DOI: $10.1039 / c 8 r a 06978 f$

rsc.li/rsc-advances

\section{Structural characteristics, analytical techniques and interactions with organic contaminants of dissolved organic matter derived from crop straw: a critical review}

\author{
Bin Wang, ${ }^{\text {ab }}$ Chang Liu, ${ }^{\text {ab }}$ Yuwei Chen, ${ }^{\text {ac }}$ Faqin Dong, ${ }^{\text {ab }}$ Shu Chen, (D) *ab Di Zhang*d \\ and Jingping Zhu ${ }^{\mathrm{ab}}$
}

Dissolved organic matter (DOM) represents one of the most mobile and reactive organic compounds in an ecosystem and plays an important role in the fate and transport of soil organic pollutants, nutrient cycling and more importantly global climate change. Advances in environment geochemistry in the past two decades have improved our knowledge about the genesis, composition, and structure of DOM, and its effect on the environment. Application of analytical technology, for example UV-visible spectroscopy (UV-Vis), Fourier transform infrared spectroscopy (FTIR), Nuclear magnetic resonance (NMR) spectroscopy, and three-dimensional fluorescence spectroscopy (3D-EEM) have resulted in these advances. At present, crop straw, as a part of energy development strategy, is mainly used for soil amendment, fodder, fertilizer and industrial materials. Moreover, the fermentation and decomposition of straw should be also promoted for ecological agriculture. However, few studies have focused on the structural properties of DOM derived from crop straw in farmland soil. In this article, DOM derived from crop straw, which is abbreviated to "CDOM", presents active physicochemical properties that can affect the migration and bioavailability of organic contaminants (OCs) in terrestrial ecosystems. The objectives of this review paper are: (i) to discuss the structural characteristics, analytical techniques and interactions between CDOM and OCs in farmland soil; (ii) to present a critical analysis of the impact of CDOM on the physicochemical transformation and transport of OCs in farmland soils; (iii) to provide the perspectives in future research. Therefore, the findings obtained from this study can be utilized to evaluate the relations of interactions between CDOM and OCs in agricultural soils, in order to support some suggestions for future development in agricultural waste recycling, buffering of organic pollution, and the effect on the global carbon cycle.

\section{Introduction}

With economic and social development, organic pollution in soils has become a common environmental issue. ${ }^{1}$ The organic contaminants (OCs), originating from sewage irrigation, animal manure, pesticide application, atmospheric deposition and waste dumping, have entered into farmland soils, and

${ }^{a}$ School of Environment and Resource, Southwest University of Science and Technology, Sichuan 621010, PR China. E-mail: crick_chen@hotmail.com; Fax: +86 816 2419018; Tel: +868162419018

${ }^{b}$ Key Laboratory of Solid Waste Treatment and Resource Recycle, Ministry of Education, Southwest University of Science and Technology, Sichuan 621010, PR China

'Department of Chemistry and Biochemistry, Laurentian University, Sudbury P3E 2C6, Canada

${ }^{d}$ Faculty of Environment Science and Engineering, Kunming University of Science and Technology, Yunnan 650500, PR China. E-mail: zhangdi2002113@sina.com; Tel: +86 15887215550 participated in different natural geochemical and biological processes. ${ }^{2-4}$ The source, composition and structure of dissolved organic matter (DOM) with the molecular weight distributed widely are very complex. ${ }^{5} \mathrm{DOM}$ is an organic polymer mixture, and widely exists in soil, sediment, aerosol, and natural water bodies. ${ }^{6}$ DOM is conventionally defined as any organic material that passes through a given filter $(0.45 \mu \mathrm{m})$, termed "dissolved" and the organic material that is retained on the filters is termed "particulate", ${ }^{7,8}$ Among the organic substances in DOM, which can pass through filters, are fulvic acid, humic acid, carbohydrates, sugars, amino acids, proteins, lipids, organic acids, phenols, alcohols, acetylated amino sugars. Most of its composition is bioavailable and can be easily absorbed and utilized by soil microorganisms., ${ }^{9,10}$ DOM plays dominant role in the global circulation, speciation, toxicity, transfer and transformation of OCs. ${ }^{11,12}$ Significantly, DOM derived from crop straw, which is abbreviated to "CDOM", presents active physicochemical properties that can affect the 
migration of OCs and bioavailability of OCs in terrestrial ecosystems. ${ }^{13}$

Through various interactions (van der Waals forces, hydrophobic interactions, and electron donor-acceptor), DOM binds OCs and affects the bioavailability of freely dissolved and bound OCs. DOM-sorbed pollutants normally have lower bioavailability compared to the pollutants freely dissolved in aqueous phase. Published research documented the importance of DOM in sorbing OCs and inhibiting their bioavailability. The inhibiting of bioavailability can result in a decrease biodegradation of OCs. ${ }^{14}$ Meanwhile, previous studies have shown that contaminant toxicity to target organisms is altered by the presence of DOM. Contaminants can bind to DOM and this may alter the bioavailability and subsequent toxicity of the contaminants. ${ }^{15}$ Perminova et al. ${ }^{16}$ found the toxicity of PAHs to Daphnia magna was alleviated by humic acids (HA) and fulvic acids (FA). Yang et $a{ }^{17}{ }^{17}$ also proved that phenanthrene would be adsorbed preferentially by aromatic carbon rich lignin than paraffinic carbon rich wax, thus lowering its bioavailability. However, several reports showed that the presence of DOM would also increase the bioavailability of OCs. ${ }^{18}$ Lin et al. ${ }^{19}$ found that DOM promoted the bioavailability of pyrene when the freely dissolved concentration of pyrene was kept constant. Also, as suggested by Cai $e t a l .{ }^{20}$ DOM enhanced the bioavailability of phenanthrene by facilitating the microbial accessed to DOMphenanthrene complex. The enhancement of polyferric aluminum sulfate (PFAS) bioaccumulation by Daphnia magna after addition of DOM at a low level was also found by Xia et al. ${ }^{21}$ Therefore, DOM is a key component of the global carbon cycle and it is considered as the most active chemical group in terrestrial and aquatic ecosystems with its contribution of natural ligands and adsorption carriers in the environment. ${ }^{7,22}$

The content of DOM (less than $0.5 \%$ of soils organic carbon (SOC)) in soil was generally relatively low, but it was one of the most active components in the soil ecological environment, it also may most rapidly reflect changes in the condition of a soil. ${ }^{23}$ As the organic fertilizer application and direct straw returning are widely used measures for farmland soil improvement in agricultural country, a mass of exogenous DOM are being taken into farmland leading to an increase in DOM content of farmland soil. ${ }^{24,25}$ According to relevant report, the content of DOM always in a dynamic process. Kalbitz et al. ${ }^{26}$ contend that content of DOM was effected by four factors: (i) properties of soil solid phases (ii) environmental factors (iii) chemical properties of soil solutions (iv) decomposition and transformation of DOM. However, the content of DOM in soil differs in one soil type from another. Also, the type of straws and pretreatment methods make difference. Nowadays, more and more OCs is being poured into farmland soil due to agricultural activities such as fertilization, sewage irrigation, and land application of sludge. ${ }^{27,28}$ DOM has a number of important ecological functions. For instance, DOM binds to a variety of heterogeneous organic substances or OCs to modify their behaviors in soils..$^{29,30}$ Also, DOM mitigated the effect of OCs by reducing their free concentrations and consequently accumulation by organisms. ${ }^{31,32}$ Thus, DOM plays important roles in many chemical and biological processes in soils. ${ }^{33}$
To date, most studies have focused on the influence of DOM on toxicity of hydrophobic organic chemicals in aquatic organisms. ${ }^{34}$ However, more researches need to be done on the release of DOM from the decomposition process of crop straw and the biochemical effect of CDOM on OCs availability. The objectives of this review paper are: (1) to discuss the structural characteristics, analytical techniques and interactions between CDOM and OCs in soil; (2) to present a critical analysis of the impact of CDOM on the physicochemical transformation and transport of OCs in soils; (3) to evaluate the changes in toxicity of OCs caused by CDOM; (4) to summarize the research achievements at present and to provide the perspectives in future research. Ultimately, it improves our understanding of OCs transfer within the farmland soil system, and provide information for strategy that reduces the environmental risks of the OCs to crop production.

\section{Sources and structure of DOM in farmland soil}

\subsection{Sources of DOM in farmland soil}

It is generally known that DOM is a mixture composed of various compounds, and each component is greatly different in organic carbon content, molecular weight distribution, and functional groups. ${ }^{35}$ The structures and chemical reactivities of DOM can vary in space and time, depending in large part on the source materials and subsequent degradation, transformation, and/or mixing processes. ${ }^{36}$ External sources of DOM in farmland soil are mostly supplied from the surrounding soils which are covered with a wide array of organic source materials. These terrestrial sources are likely to contain plant debris, detritus, living organisms, algae and straw. ${ }^{37}$ Moreover, the different sources of DOM inevitably affect its distribution characteristics and structural properties, degradation process and interaction with soil components, which ultimately affected the biogeochemical processes of DOM in farmland soil. ${ }^{38-40}$ Similarly, in the latest studies, Martin $e t$ al. $^{41}$ studied the sorption affinities of 4 pharmaceuticals applied in solute mixtures to soils taken from different horizons of 3 soil types. This experiment revealed that the content of organic matter would be different for various types of soil. Moreover, the sorption of OCs in soil may be affected by the different of DOM content and characteristic. Bi et al. ${ }^{42}$ reported that the DOM derived from different sources enhanced the uptake of OCs by soil compared with the control treatment. In the case of the OCs, sorption affinity of compounds decreased with soil depth, i.e. decreased with soil organic matter content. The forms of contaminants may also be affected. Badejo et al. ${ }^{43}$ found that lead isotopic composition (Pb-206/Pb-207 ratios) depends on soil organic matter content either fresh/poorly humified or humified and effect its degradation process. Thus, for more information of DOM contents, it can take correct precautions and measures to contaminants.

At present, there are vast numbers of crop straws in China, which have many types and are widely distributed. ${ }^{44}$ Research 
into the utilization of crop straws has increased in recent years due to its renewability, widespread availability, and its potential value that can be added by the generation of straws-based products. ${ }^{45}$ Climatically, the Western Sichuan Plain is a subtropical humid monsoon zone. ${ }^{46}$ The plain has been continuously managed, reconstructed and expanded, the land utilization rate has reached more than $60 \%$, and has become the main agricultural production base in China. ${ }^{47}$ The Western Sichuan Plain is the main producing area of wheat-rice, canolarice two cropping, from the principle of minimum dynamical soil, reducing soil exposed on the basis of conservation tillage and achieving the goal of covering the surface with the rice and wheat. ${ }^{48}$ In present, a series of reviews were conducted to introduce the dynamic properties of CDOM decomposition in farmland soils. Recent studies have shown that DOM from three types of straw (barley, rice, and wheat) and natural organic matter (NOM) isolates were investigated in terms of their photochemical properties and reactive oxygen species (ROS) generating abilities. Results demonstrated that the DOM derived from the aeration decomposition of barley straw yielded the best formation efficiencies of hydrogen peroxide $\left(\mathrm{H}_{2} \mathrm{O}_{2}\right)$ and hydroxyl radicals $(\cdot \mathrm{OH})$ under solar-simulated irradiation in all organic matter samples. So, the characteristics of DOM released from the decomposing process of different straws may also differs. ${ }^{49}$ Although DOM are from the same source, the results of the present study demonstrate that chemical characteristics of fresh DOM and degraded DOM which both were extracted from the straw of maize, they are greatly diverse in components, functional group species, molecular weight distribution, etc. ${ }^{\mathbf{5 0 , 5 1}}$ Hence, understanding the characteristics and role of the CDOM is important for facilitating the potential application in agricultural environments. ${ }^{45}$

\subsection{Structure of CDOM in farmland soil}

CDOM is one of the most active compositions in soils, which can affect the transport and decay of soil pollutants, and the availability of soil nutrients (C, N, P, S, etc.). ${ }^{52} \mathrm{CDOM}$ comprises a huge variety of organic substances including chromatographically unidentifiable humic substances and chromatographically identifiable biomolecules such as carbohydrates, amino acids, fatty acids, etc. ${ }^{53,54}$ Humic substances (HS), such as humic and fulvic acids, are conventionally defined as heterogeneous organic materials extracted at alkaline $\mathrm{pH}$ and, according to the recent concept regarding soil organic matter (SOM), represent aggregates of small molecules with common properties, such as high aromaticity reflecting an excess of phenol groups. ${ }^{55}$ Non-humic substances mainly derive from animals, plants, microorganisms and their residues, in the forms of sugars, amino acids, proteins, lignin and organic acids. ${ }^{56}$ Humic acids are the major extractable component of soil humic substances and are the primary organic compounds of soil. The molecular size of humic acids range from approximately $10000 \mathrm{Da}$ to $100000 \mathrm{Da}$, about 35\% of the humic acid molecules are aromatic, while the remaining components are in the form of aliphatic molecules. Fulvic acids are a mixture of weak aliphatic and aromatic organic acids, the size of fulvic acids are smaller than humic acids, with the molecular weights range from approximately $1000 \mathrm{Da}$ to $10000 \mathrm{Da}^{57}$

As early as 1976, the researchers took the lead in adopting $\mathrm{XAD}$ resin tandem anion and cation exchange resins to divide DOM into six components: hydrophobic base (HOB), hydrophobic neutrals (HON), and hydrophobic acid (HOA), hydrophilic acid (HIA), hydrophilic base (HIB), and hydrophilic neutrals (HIN). ${ }^{58-60}$ This report intends to enrich the hydrophobic, neutral, and hydrophilic components of CDOM by XAD-8/XAD-4 resin, most traditionally based on the hydrophilicity and acidity of CDOM components. According to one study the hydrophobic fraction consists of soluble degradation products of lignin; it is enriched in structural ortho-hydroxybenzene fragments, which ensure its selective sorption and strong retention, but the hydrophilic fraction composes the major portion of labile DOM in soils. ${ }^{61}$ Thus, soil CDOM containing a great deal of lower molecular weight fractions or hydrophilic fractions is more mobile and readily biodegradable, compared to CDOM with larger molecular weight or hydrophobic fractions.

It is widely recognized that the humic substances (HS) in soils and sediments is the principal factor controlling sorption of organic compounds. Moreover, it has been established that the organic carbon-normalized partition coefficient $\left(K_{\mathrm{oc}}\right)$ is a critical factor in determining hydrophobic organic chemical distributions in most systems. The variation in quality of the HS strongly affects the transport of toxic organics $\left(K_{\mathrm{oc}}\right)^{62}$ For example, Chefetz et al. ${ }^{63}$ showed that the polarity and aromatic component of the natural organic matter influence the binding of polycyclic aromatic hydrocarbons (PAHs). The sorption of naphthalene increased with increasing aromaticity and decreasing polarity of soil organic matter. A strong correlation was observed between $K_{\mathrm{oc}}$ for pyrene and the molecular weights, molar absorptivities at $280 \mathrm{~nm}$, an aromaticity of the HS. Panagiotopoulos et al. ${ }^{64}$ investigated the relations between $\log K_{\mathrm{oc}}$ and absorptivity, $\mathrm{H} / \mathrm{O}$ ratio, and the concentration of phenolic group of the dissolved organic matter surrogates. The (bio) degradation of soil DOM does not necessarily rely upon the molecular weights distribution. Previous studies on DOM from forest soil organic horizons showed that both the highest $(>100000)$ and lowest $(<1000)$ molecular weight organic fractions can be (bio)degradable. Thus, the majority of DOM compounds in soil solution are usually shifted towards lower molecular weight $(<100000$ size range) as a result of the degradation of initial litter organic matter under oxidised conditions. In soils, several organic compounds formed during the decomposition of SOM or lysis of microbial cells can sorb onto functional sites of mineral surfaces (Fe(III) and $\mathrm{Mn}$ (Iv) oxyhydroxides and clays) or coprecipitate with newly formed secondary minerals. In particular, DOM enriched with aromatic moieties or hydrophobic carbon moieties (i.e. alkyl chains) was reported to be preferentially bound to mineral surfaces. ${ }^{65}$ Thus, CDOM can not only serve as an important source of energy for microbial growth and reproduction, but can also regulate the environmental behavior of pollutants in soil, such as their solubility, migration and transformations. ${ }^{42,66}$ 


\subsection{Effecting factors of the content and nature of CDOM}

The change of DOM contents is affected by many factors, for example, anthropogenic and natural factors and so on. Especially DOM is a balanced dynamically with complex process in farmland soil. DOC would be affected by straw mulching, organic and inorganic fertilizer, etc. Chang et al. ${ }^{67}$ had been demonstrated in their experiments. In moisture soil, green manures and soils were sampled in situ at the ploughed stage of green manures. A 56 day laboratory incubation experiment was conducted to simulate the dynamic changes of soil DOM influenced by the decomposition of green manures, the composition and ultraviolet-visible spectrum parameters of soil DOM were investigated at different incubation stages. ${ }^{68,69}$ Results showed that green manures could increase the dissolved organic carbon (DOC), the total organic acids (TOAs) and total carbohydrate (TCs) contents, and all treatments were reached a peak on the 1st day and decreased later. Meanwhile, green manures could increase the contents of DOM and its aromaticity, hydrophobic percentage, humification degree and average molecular weight, and could be increased and the stability of DOM could be enhanced accordingly ${ }^{67}$ The content of DOM also can be affected by different pretreatment methods. Chen et $a l .{ }^{70}$ understand as to how pre-treatment of a soil will affect the characteristics of DOM, since this fraction may be strongly influenced by a soil's water content. The effect of two different pre-treatments on DOM from the A-horizons of a large variety of ecosystems and regions were compared. And it analyses quantity and spectroscopic properties of soil DOM. The results show that DOM extracted from soils is not comparable. So, the content of DOM always in a dynamic process. Soil moisture is another important factor affecting on DOM. there were a lot of discussions the change of DOM contents in wetting-drying soil. ${ }^{71}$ All the above results are in correspondence with theoretic analysis that DOM contents significantly increased with greater soil moisture. Some researchers show that the concentration of DOC in soil solution was significantly increased at the initial stage of flooding. The depth of soil can also effect content of CDOM. On the vertical direction, CDOM showed a decreasing trend with the increase of soil depth. ${ }^{72}$ In addition, it contents changed with the seasons, in order of spring $>$ summer $>$ autumn $>$ winter. The CDOM contents in horizontal direction, the moisture content, $\mathrm{pH}$, and soil microorganism affected the humidification and mineralization processes of organic matter, which further affected the variation of DOM structure. ${ }^{73}$ The structure of CDOM affect not only the interaction of CDOM and OCs directly but also the features of soil surface, which may eventually result in the alteration of OCs activity in soil.

\section{Analytical techniques on the properties of CDOM}

In the past two decades, analytical tools for determining DOM chemistry have significantly advanced from bulk chemical characterization by elemental analysis to simple molecular-level approaches represented by e.g. UV-visible spectroscopy (UV-Vis), three-dimensional fluorescence spectroscopy (3D-EEM) and Fourier transform infrared spectroscopy (FTIR), as shown in Fig. $1 .^{74-78}$ These rapid and relatively inexpensive techniques are widely used to obtain information on sources, composition and sometimes reactivity of DOM, so it is in CDOM. Also, mass spectrometry (MS) and nuclear magnetic resonance (NMR) spectroscopy can be used to provide useful information on DOM chemistry (Table 1). ${ }^{79-82}$

\subsection{Elemental analysis}

Element analysis is one of the most common methods to record DOM structures. There are some researches who have reported a characterization study of soil-derived DOM across the Three Gorges Reservoir (TGR, China), using elemental and optical analysis, infrared spectroscopy. ${ }^{83}$ With elemental analysis, basic information on the nature of DOM also can be obtained through simple molar ratios. ${ }^{84}$ For instance, $\mathrm{C} / \mathrm{H}$ can indicate the degree of unsaturation and aromaticity of DOM, while $\mathrm{O} / \mathrm{C}$ or $(\mathrm{N}+\mathrm{O}) / \mathrm{C}$ indicates the polarity of the DOM. ${ }^{85}$ The results show that the soil DOM from the TGR area is a mixture of "allochthonous" (i.e., plant-derived/terrigenous) and "autochthonous" (i.e., microbial) origins. The terrigenous DOM is composed primarily of phenolic and aliphatic structures from lignin and aliphatic biopolymers (i.e. cutin, suberin), respectively. ${ }^{83}$ Recent research shows that fractionation of DOM from farmland soils was conducted by using XAD-8 resin into HOA, and HON, and their structural characteristics were studied by means of elemental composition, FTIR and ${ }^{1} \mathrm{H}-\mathrm{NMR}$ spectroscopy. ${ }^{\mathbf{8 6 , 8 7}}$ Separated by this technique, the major portion of the DOM mainly characterized HON, while the HOA fraction contained a large amount of carboxyl groups but fewer aromatic groups with a higher quantity of carbohydrates compared to that of fulvic acid (FA). ${ }^{88}$

\subsection{UV-Vis and FT-IR spectroscopies}

UV-Vis spectra reflect the characteristics of DOM in terms of aromatic compounds and conjugated systems. Combining DOM characterized by UV-Vis spectroscopic indices and elemental analysis is useful to distinguish DOM straw sources. $^{89}$ Single spectral technology cannot comprehensively reveal structural features and sources of DOM, therefore, in some studies UV-Vis and the 3D-EEM spectroscopy were applied to investigate the structure and origin of DOM from soils. ${ }^{90}$ It can serve to provide a theoretical basis for the further study of the DOM's effect on the migration and transformation of OCs.

FT-IR spectroscopies can contribute to DOM along the soil depth profile to better understand elemental compositions. ${ }^{{ }^{11}}$ Though FT-IR, UV-Vis and fluorescence spectra results suggested that DOM from the upper horizons was enriched with aromatic and humic structures while that was rich in aliphatic carbon, which supported the obtained by spectroscopic characteristics of DOM from the lower horizons. ${ }^{\mathbf{4 2}}$ Choi et al. ${ }^{92}$ investigated DOM in moist acidic tussock tundra to better understand elemental compositions, in this study, the soil extracts were analyzed using a 15 tesla FT-IR 


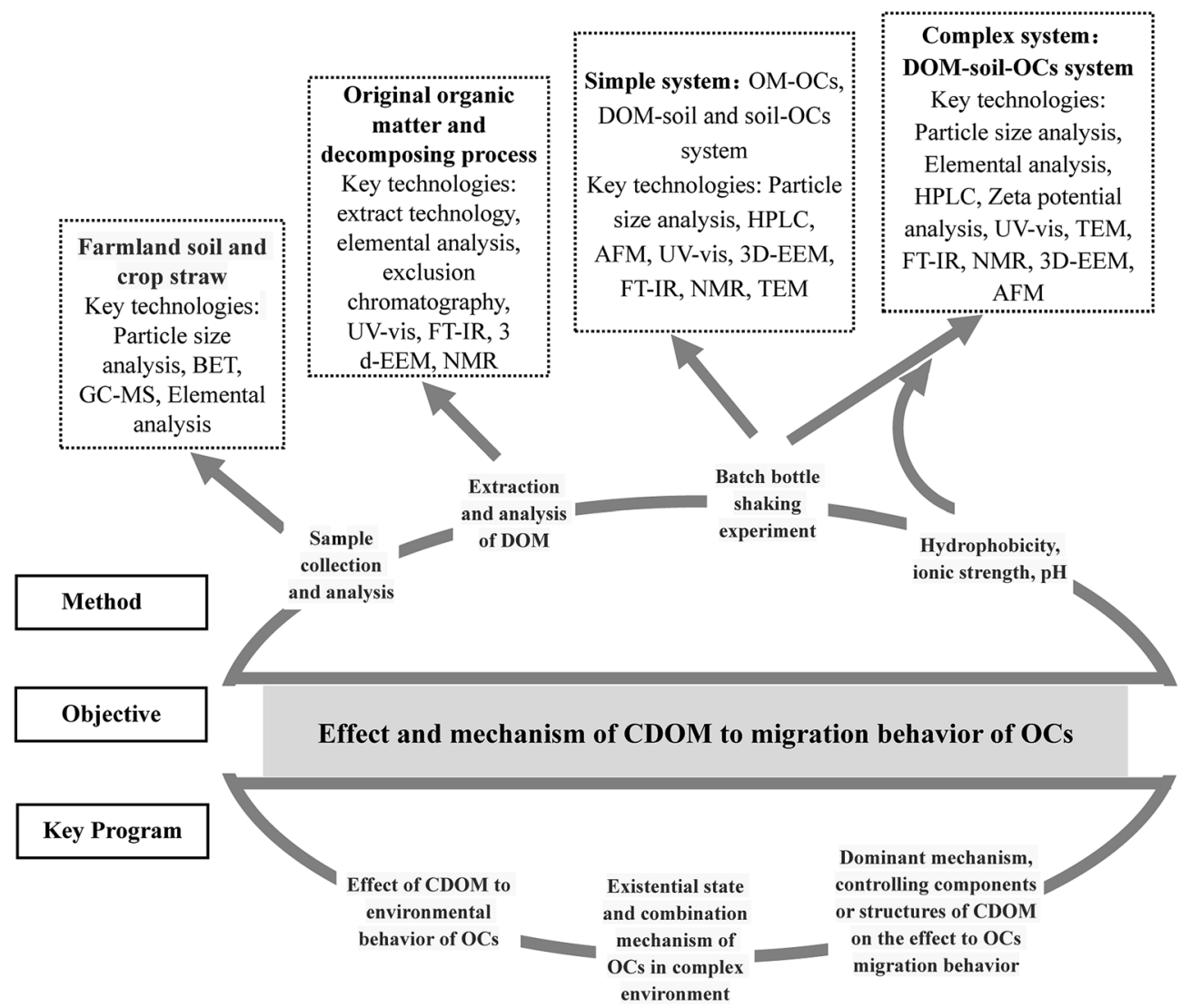

Fig. 1 Technology roadmap of interactions with organic contaminants of DOM derived from crop straw.

spectrometer in positive and negative ion modes via electrospray ionization. The results of this analysis revealed that the deeper organic soil exhibits less CHON class and more aromatic class compounds compared to the surface organic soils, thus implying that the deeper soil has decomposed more and consequently possessed the recalcitrant materials. ${ }^{93}$ Recent research, the fractional composition of DOM and the chemical nature of humic and fulvic acids were studied in lysimetric waters from forest soils of different altitudinal zones in the Sikhote Alin Range. ${ }^{94,95}$ The elemental composition, infrared absorption spectra, concentrations of acid functional groups of humic and fulvic acids were determined. The soils of high-mountain zones had stronger acidic properties of humic and fulvic acids in comparison with the soils of low-mountain zones. ${ }^{96}$ Moreover, infrared spectroscopy can provide functional information of DOM, and inform on the composition of each functional group in the dynamic change of DOM.

\subsection{Three-dimensional fluorescence spectroscopy (3D-EEM)}

3D-EEM can show the distribution of DOM in unsaturated structure and different types of fluorescent materials humic and fulvic acids fluorescence are mainly attributed to carboxyl, phenolic hydroxyl or carbonyl groups. ${ }^{97}$ EEM

Table 1 Analytical techniques for structural characteristics of DOM derived from crop straw

\begin{tabular}{lll}
\hline Analytical techniques & Function & Advantage \\
\hline $\begin{array}{l}\text { Elemental analysis } \\
\text { UV-Vis }\end{array}$ & $\begin{array}{l}\text { Element composition and content of CHNOS } \\
\text { Functional groups, chemical bonds }\end{array}$ & $\begin{array}{l}\text { Universality and the easy to operate } \\
\text { Don't need special handling and ease of } \\
\text { operation }\end{array}$ \\
$\begin{array}{l}\text { FT-IR spectroscopies } \\
\text { Three-dimensional fluorescence } \\
\text { spectroscopy (3D-EEM) }\end{array}$ & $\begin{array}{l}\text { The form of functional groups } \\
\text { Fuclear magnetic resonance (NMR) } \\
\text { structure of DOM }\end{array}$ & $\begin{array}{l}\text { High sensitivity and only needs few sample } \\
\text { High sensitivity and do not destroy samples }\end{array}$ \\
& important fingerprint information for the & Higher accuracy and sensitivity
\end{tabular}
characterization of DOM structures 
spectroscopy coupled with parallel factor (PARAFAC) and principal components analysis (PCA) was a useful method to characterize fluorescent components of DOM, by specific indices, such as the humification index (HIX). For instance, a study of organic materials and their sources in upstream and downstream waters of dissolved organic carbon (DOC) was performed by EEM spectroscopy, PARAFAC analysis and photo-microbial experiments. ${ }^{\mathbf{9 8}, 99}$ The upstream DOM was mostly composed of one component that had a fulvic acidlike substance whereas downstream DOM was composed of two components with mixtures of tryptophan-like and fulvic acid-like substances. ${ }^{\mathbf{1 0 0}}$

Also 3D-EEM can be used to analyze the interaction between DOM and OCs. By using the 3D-EEM technology, together with the fluorescence regional integration (FRI) quantitative method, the long-term effects of pesticide residues under low concentration of natural DOM were analyzed. These results suggest that the distribution of different types of pesticide residue in the soil was influenced by different components at different levels of significance. Moreover, the humification degree of soil organic matter was an effect of DOM on the pesticide residues in the soil. ${ }^{101}$

\subsection{Nuclear magnetic resonance (NMR)}

${ }^{13} \mathrm{C}-\mathrm{NMR}$ spectroscopy can provide important fingerprint information for the characterization of DOM structures, such as the relative content of various types of carbon (aliphatic, aromatic, carboxyl, carbonyl, amine, etc.). ${ }^{7,102}$ Researchers have studied the direct conversion of DOM from the aromatic compounds and unsaturated structures to carboxylation and hydroxylation products by using a flow-based design NMR spectroscopy and direct sunlight interface. ${ }^{103}$ The phenols, carbonyls and carboxylic acids can enhance the interaction of DOM and organic contaminants, which further regulated the migration and transfer processes of contaminants in farmland soils. ${ }^{104}$ For instance, a recent study was conducted to understand the influence of dibutyl phthalate (DBP) adsorption kinetics and isotherms in soils under different concentrations of extraneous DOM, by using FTIR and NMR. The NMR indicated that the intra-molecular and intermolecular hydrogen bond interactions of carboxylic acids, aromatic $\mathrm{CC}$ and $\mathrm{CO}$ in amides were involved in DBP adsorption in soils. Therefore, the addition of DOM may increase adsorption of DBP in soils. ${ }^{101}$ Also, NMR spectroscopy can be used to evaluate the aromatic compounds and their degradation products in samples influenced by OCs and its biodegradation. ${ }^{105}$ It can make us to enable a comprehensive level understanding of the DOM with respect to in composition and structure. The role of natural DOM as potential cosubstrate and detoxification reactant may improve future remediation strategies.

Each of the above indicators, confirm and complement each other. The integration of multivariate information can be more useful for accurately understanding the nature of crop straw and its decomposition process DOM. This can not only correlate the changes in the composition of soil organic matter, but help to understand the source of straw provides the basis for the mechanism of interaction between DOM and OCs.

\section{Interaction between CDOM-soil- $\mathrm{OCs}$}

\subsection{Benefits of DOM on soils}

The availability of crop straw in agriculture is very important for the sustainability of biomass supply. Returning crop straws to fields can improve the soil quality by increasing the soil CDOM content, enhancing the microbial activities as well as their enzymes production, and improving the soil texture. ${ }^{24}$ Due to the restitution of crop residues and the application of organic fertilizer during the cultivation process, the exogenous CDOM can augment its concentrations in agricultural soil. ${ }^{106-108}$ SOM content and composition affect both soil structure and adsorption properties; so, water retention may be affected by changes in soil organic matter. ${ }^{107}$ Thus, CDOM is widespread in natural environments where it has an important role in determining the balance and long-term accumulation of element content (carbon, nitrogen, and phosphorus) in soil. ${ }^{109}$ Incorporation of organic matter had been put into practice as soil amendment in protect the soil from solar energy to reduce evaporation and aid in moisture retention to decrease soil water loss. Several studies conclude that soil moisture, rather than temperature, has the most significant influence on soil organic matter. Moreover, soil organic matter had been applied as an important factor to predict soil water retention characteristics. Rusan et al. ${ }^{110}$ were confirmed the function organic matter incorporation into soil continuously in improving soil water retention and plant growth environment. Conversely, soil capacity as well as the crop productivity directly depends on soil degradation and pollution, which determine effecting of soil organic matter and biological diversity.

\subsection{Interaction mechanism of CDOM-soil-OCs}

At present, some researches on the interactions of DOM-OCs are mainly concentrated in the environmental medium of humic substances DOM as soil, lakes, rivers, wastewater, etc. ${ }^{111-114}$ With regard to the mechanism of DOM binding between OCs in farmland soil, DOM is considered to be one of the most important components due to its active physicochemical properties. There have been many theories and empirical studies in this field ${ }^{115}$ So far there are many mechanisms for the combination of DOM and OCs, and the same would be true of CDOM. It mainly includes hydrogen bonding, ligand exchange, hydrophobic particle distribution, covalent bonding, chelation, $\pi$ bond interaction, and electron transfer. ${ }^{116-118}$ In the process of combining OCs with CDOM components and a variety of mechanisms coexist, often associated with the soil environment and the property of organic compounds. ${ }^{119}$

The contents of organic matter in different crops were different so that the contribution of the decomposition process to CDOM of soil must be different. ${ }^{120}$ Wei et al. ${ }^{121}$ studied that crop straw decomposition process can be divided into three stages: (1) leaching release where the soluble components in the 
crop straws are rapidly leached into the soil by irrigation and rain erosion; (2) the degradation of $\mathrm{N}$ and $\mathrm{P}$ materials is easy to be degraded; (3) organic matter degradation with mainly polysaccharides, lignin, dense kink of lipids and so on as which are the main released matters, also the persistent cellulose, hemicellulose and macromolecular protein were decomposed. In the case of crop straw after leaching, the elemental distribution and chemical properties of the CDOM released by the decay process are still in a dynamic state. ${ }^{\mathbf{1 2 2}}$ As the properties of soil component are closely related to the environmental behavior of OCs, the CDOM will have an important effect on the migration behavior of OCs in farmland soil, as shown in Fig. 2(a).

The migration process of OCs in farmland soil is likely to be involved in the process and mechanisms of CDOM, such as the one shown in the Fig. 2. CDOM contains a large number of oxygen functional groups, of which hydroxyl, can combine with groups on organic molecules to form $\mathrm{H}$ bonds. ${ }^{123}$ The $\mathrm{H}$ bonding plays an important role in the adsorption of several non-ionic polar pesticides, such as 2,4-D, 2,4,5-T and dicamba, $\mathrm{H}$-bonding also can be formed between - $\mathrm{COOH},-\mathrm{COOR}$ groups and organic matter, so as to control the OCs in the soil. ${ }^{\mathbf{1 2 4 , 1 2 5}}$ As shown in Fig. 2(b), recent studies further reported that CDOM can form complexes with OCs or promote OCs migration in the soil by competing with the adsorption sites of soil particles. ${ }^{\mathbf{1 2 6 , 1 2 7}}$ It can also enhance the adsorption capacity of OCs by coadsorption or cumulative adsorption. ${ }^{128}$ The so-called coadsorption is OCs being preferentially adsorbed to one or more components of the CDOM leading to the formation of

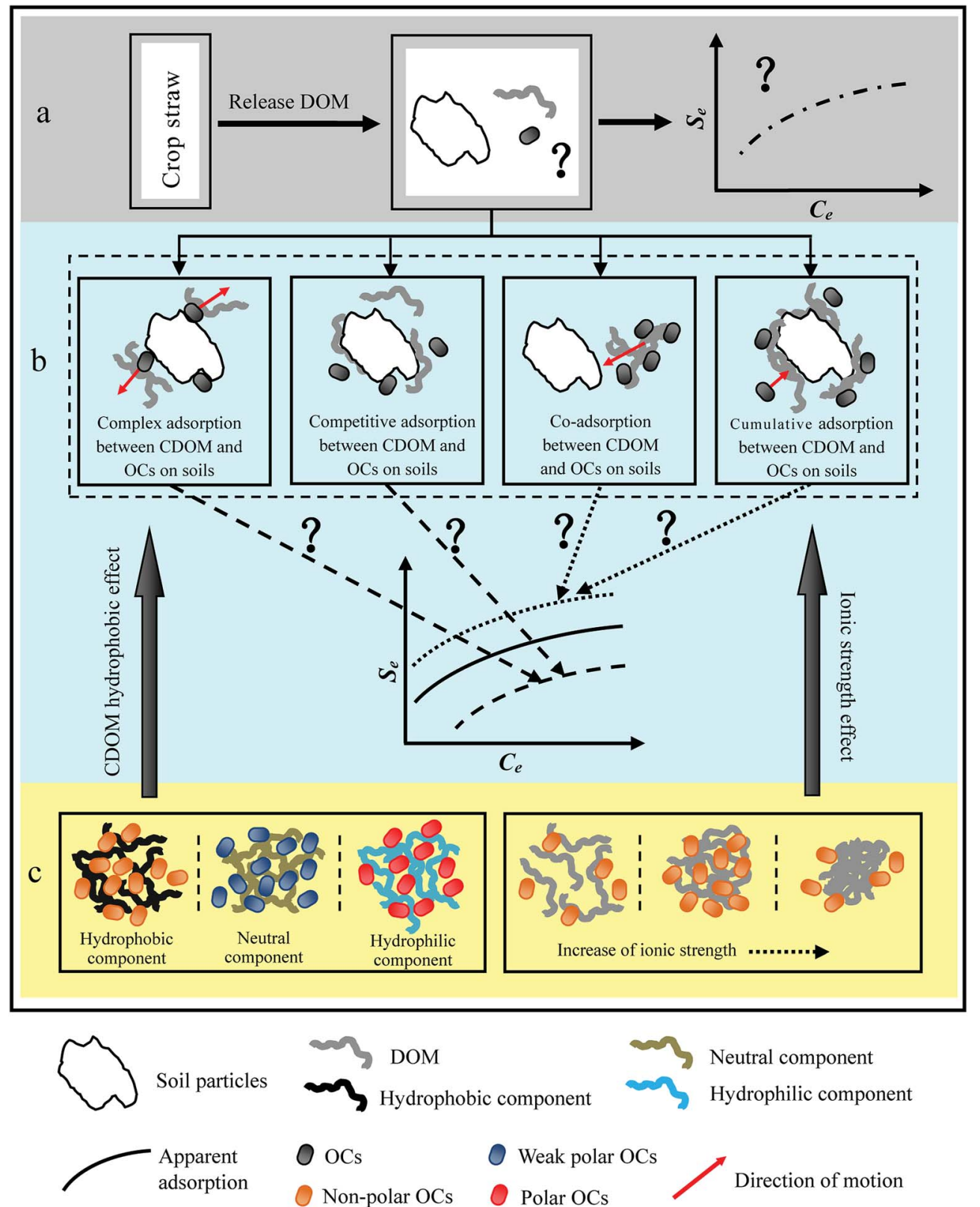

Fig. 2 The process mechanism of interactions between CDOM and OCs. Note: Se and Ce are solid-phase and liquid-phase concentrations, respectively. 
complexes and CDOM at the same time adsorbed to the soil particles. And cumulative adsorption means that one or more components of CDOM are preferentially adsorbed by soil particles and the adsorption capacity of soil particles to certain OCs is enhanced with the increase of DOM adsorption capacity. ${ }^{\mathbf{1 2 9}}$ Some researchers proposed the hydrophobic, neutral and hydrophilic components in CDOM by XAD-8/XAD-4 resin extraction and separation to study their effects on the migration behavior of OCs in soils, as shown in Fig. $2(\mathrm{c}) \cdot{ }^{130,131}$ These results indicated that the higher proportion of hydrophobic alkyl carbon and aromatic carbon in plant residues, the less biodegradable, and the higher proportion of hydrophilic polysaccharides, the more easily degraded, usually completed in a few months. ${ }^{132}$

Nowadays, an extensive effort has been devoted to understanding sorptive interactions between HOCs and natural DOM, particularly, the structure-activity correlations. Many studies reported that sorption of apolar HOCs (e.g., polycyclic aromatic hydrocarbons/PAHs, halogenated compounds, etc.) to DOM positively correlated to its aromaticity, which was attributed to the facilitated van der Waals (dispersion) and/or p-p interactions in sorption. ${ }^{\mathbf{1 3 3 , 1 3 4}}$ The strong binding of apolar HOCs to DOM is often attributed to the abundance of aromatic moieties, which have relatively high electronic polarizability and hence facilitate van der Waals (dispersion) interactions with HOC molecules. ${ }^{135}$ Furthermore, the aromatic moieties of DOM can induce additional $\mathrm{p}-\mathrm{p}$ coupling/stacking interactions with the $\pi-\pi$ electron-bearing HOCs (such as PAHs). Instead, the aliphatic content of DOM was suggested to play a more important role in sorption of apolar HOCs. Additionally, the sorption affinity of apolar HOCs was often found to be inversely proportional to the polarity of DOM, suggesting the dominant role of hydrophobic partition. Regarding the sorption of polar organic pollutants, the presence of HA may have different effects as compared to HOCs due to that the two types of organic pollutants have different sorption mechanisms. ${ }^{136,137}$ Guo et $a l .{ }^{138}$ studied that DOM impact on polar organic pollutants would be more pronounced at low DOM concentration values due to competition of DOM and polar O-containing pollutants for mineral surface sites. The process may be less significant at higher DOM concentration values because mineral surfaces become less selective towards oxygenated components. Therefore, non-polar OCs are more susceptible to approach lowpolarity CDOM, while strongly polar OCs have stronger bonds with polar aromatic CDOM. ${ }^{139}$ When the hydrophobic component is dominant, CDOM may promote desorption of non-polar OCs from farmland soils. Also in hydrophobic microenvironment CDOM may increase the adsorption of non-polar OCs, while the hydrophilic components may accelerate the release of soil particle surface polar OCs. ${ }^{\mathbf{4 0}}$

In the DOM-soil-OCs complex systems, the conformation of DOM is affected by its chemical and structural properties (e.g., aromaticity/aliphaticity, polarity, and molecular weight) as well as solution chemistry conditions such as $\mathrm{pH} .{ }^{\mathbf{1 4 1}}$ Low $\mathrm{pH}$ and high cationic intensity will reduce the repulsion between DOM molecules or molecules, promote the agglomeration of DOM molecules and change the hydrophobic nature of the system, but this effect is not monotonous..$^{\mathbf{8 2 , 1 4 2 , 1 4 3}}$ DOM particles contain abundant carboxyl and phenolic groups, which induce strong electrostatic repulsion when deprotonated at high $\mathrm{pH}$, consequently leading to expanded, loose molecular configuration. On the other hand, at low $\mathrm{pH}$ the facilitated protonation of the oxygen-containing functional groups would reduce the electrostatic repulsion, and hence result in more compact DOM molecules with smaller apparent particle sizes. Similar observations on deceased particle sizes of DOM and other polyelectrolytes in response to $\mathrm{pH}$ decreases were reported in previous studies. ${ }^{\mathbf{1 4 4}}$ As a result, the binding affinity of phenanthrene to DOM increased with decreasing $\mathrm{pH}$ due to the facilitated formation of compact pesudomicellar structures. A change in $\mathrm{pH}$ and ionic strength will greatly affect the interactions of DOM and polar or ionizable organic compounds. ${ }^{\mathbf{1 4 5}}$ High cations such as $\mathrm{Al}^{3+}, \mathrm{Fe}^{3+}, \mathrm{Ca}^{2+}, \mathrm{Mg}^{2+}$, or toxic trace metal ions such as $\mathrm{Cu}^{2+}, \mathrm{Mn}^{2+}, \mathrm{Pb}^{2+}, \mathrm{Cr}^{3+}$, and $\mathrm{Cd}^{2+}$ may affect $\mathrm{CDOM}$, monovalent ions such as $\mathrm{Na}^{+}$and $\mathrm{K}^{+}$can also affect CDOM. ${ }^{\mathbf{1 4 6}}$ The presence of cations can increase the hydrophobic microenvironment of the CDOM molecules and enhance the complexation ability of non-polar OCs. ${ }^{147}$ A further increase in cations will make CDOM the number of cross-linked molecules increase, the structural tightening and hydrophobic microenvironment decrease and reduce the adsorption of non-polar OCs in soil as shown in Fig. 2(c). In addition, cations can also form complexes with certain OCs, such as amino groups in sulfamethoxazole; sulfonic acid oxygen and other groups are cationic complexation of the active site, and thereby change the existence of OCs and its behavior. ${ }^{\mathbf{1 4 8 , 1 4 9}}$ Therefore, the extent and direction of influence of CDOM on the environmental behavior of OCs depends on its own properties, characteristics, and media conditions of interaction.

\subsection{Effect of CDOM on solubility, transportation and degradation of OCs}

CDOM can affect the mobility and solubility of soil pollutants. Kim et al., octanol-water partition coefficients $\left(K_{\text {ow }}\right)$, water solubility, and dissolved humic matter (DHM)-water partition coefficients $\left(K_{\mathrm{oc}}\right)$ for 95 organic compounds were referred for estimating leachability of dioxins in the presence of DHM. The $K_{\mathrm{oc}}$ and $K_{\mathrm{ow}}$ values of dioxins were depended on chlorine content substituted. DHM in leachate influences on the solubility of dioxins, and thus the actual solubility or leachability of dioxins increase extraordinarily as increasing DHM and chlorine content. It means that dioxins abundant wastes (fly ash) should not be codisposed with organic abundant wastes (sewage sludge, food waste or bottom ash, etc.) to minimize the leachability of dioxins. Moreover, the presence of DOM reduces the harm of dioxins to soil. ${ }^{150} \mathrm{CDOM}$ plays an important role in the transport of organic pollutants in soil. Wu et al. ${ }^{151}$ investigated the mechanism of DOM on adsorption behavior of PAEs in two different soil types. DBP (dibutyl phthalate) was used as a model compound due to its high toxicity and common PAEs contaminant in soils. To understand the influence of DBP adsorption kinetics and isotherms in soils under different concentrations of DOM, batch experiments were performed in 
combination with characterization using fourier transform infrared spectroscopy (FTIR) and nuclear magnetic resonance (NMR). The results examined the effect of DOM on adsorption of DBP in soils was related to the concentrations of DOM and soil type. ${ }^{151}$ The addition of DOM at low concentrations better enhanced the effect than at high concentrations. This pattern was more dominant in the red soil and less so in the black soil. The adsorption of DBP in soils was dominated by physical adsorption irrespective of DOM hydrophobic partition played a dominant role in DBP adsorption in soils, regardless of the presence of DOM. Addition of DOM promoted adsorption of DBP in soils mainly through partition. The adsorption mechanism of DBP in the two soil types was affected by addition of DOM differently. ${ }^{152}$ The intra-molecular and intermolecular hydrogen bond interactions of aromatic CC and CO in amides were involved in DBP adsorption in red soil. Therefore, DOM played a vital role in effecting transport of DBP in soils. ${ }^{153}$

It can be seen that the environmental geochemical behavior of $\mathrm{OC}$ is controlled to a certain extent by CDOM in farmland soils. Meanwhile it is considered that the environmental behavior of OCs in soils should be studied, not only to consider the adsorption of OCs on soils, but also because it is necessary to pay attention to the effects of CDOM and decay processes on OCs migration under conservation tillage. So it is an unavoidable problem for the appropriate environmental risk assessment and quality control of farmland ecosystems.

\section{Future outlook}

CDOM plays an important role in global carbon cycling and contaminant transport. The following future outlook can be drawn on the basis of the summary:

(1) CDOM can be divided into two main types: humic substances and non-humic substances. Most studies of CDOMOCs based on the results of humic acid. However, research on the nature of CDOM is far from complete and the mechanisms of interactions between CDOM and OCs needs further study.

(2) Due to the structure of DOM is extremely complex, the information and structural properties that each analytical technique can respond to are different. Therefore, future studies are worth being undertaken to explore how this can be combined with a variety of advanced techniques further. This may result in more information for layer molecular structure of CDOM in soil.

(3) CDOM can directly or indirectly interactions with OCs by a series of reactions such as ion-exchange, adsorption-desorption, and complexation reactions in soil. The development of the environmental behavior of CDOM can gain more reasonable access to the characteristics of CDOM for control agro contaminants' pollution on soils and environmental restoration. Such investigations may be helpful for further studies aimed at risk assessment of OCs associated with application of CDOM to soils.

\section{Conflicts of interest}

There are no conflicts to declare.

\section{Acknowledgements}

This work was supported by the National Natural Science Foundation of China (Grant no. 41403081), the Key Research and Development Program of Sichuan Province of China (Grant no. 2017SZ0178), the National Key R\&D Program of China (Grant no. 2016YFC0502204) and Scientific Research Fund of Sichuan Provincial Education Department (Grant no. 18ZA0500).

\section{References}

1 Y. An, Z. Zhou, W. M. Qiao, W. Pan and Z. H. Chen, RSC Adv., 2017, 7, 42305-42311.

2 R. Cantarero, P. Richter, S. Brown, L. Ascar and I. Ahumada, Environ. Sci. Pollut. Res., 2017, 24(14), 12847-12859.

3 X. P. Liao, C. X. Zhang, L. L. Yao, J. L. Li, M. Liu, L. Xu and M. Evalde, Sci. Total Environ., 2014, 473-474, 530-536.

4 Y. Zhang, S. Hu, H. Zhang, G. Shen, Z. Yuan and W. Zhang, Sci. Total Environ., 2017, 607-608, 1348-1356.

5 W. He, Z. L. Bai, Y. L. Li, X. Z. Kong, W. X. Liu, C. Yang, B. Yang and F. L. Xu, Sci. China: Earth Sci., 2016, 59, 746759.

6 H. Hu, Y. G. Wu, N. Yi, S. Zhang, Y. J. Zhang and X. Xin, Environ. Sci. Pollut. Res., 2017, 24, 21750-21760.

7 X. X. Qu, L. Xie, Y. Lin, Y. C. Bai, Y. R. Zhu, F. Z. Xie, J. P. Giesy and F. C. Wu, Environ. Sci. Pollut. Res., 2013, 20, 7413-7423.

8 F. C. Wu and B. S. Xing, Natural organic matter and its significance in the environment, Science Press, Beijing, 2014.

9 J. Balch and C. Guéguen, Chemosphere, 2015, 119, 498-503.

10 Y. N. Liu, D. C. O. Thornton, T. S. Bianchi, W. A. Arnold, M. R. Shields, J. Chen and S. A. Yvon-Lewis, Environ. Sci. Technol., 2015, 49(6), 3366-3374.

11 I. Michael-Kordatou, C. Michael, X. Duan, X. He, D. D. Dionysiou, M. A. Mills and D. Fatta-Kassinos, Water Res., 2015, 77, 213-248.

12 X. Zhu, J. Z. Beiyuan, A. Y. T. Lau, S. S. Chen, D. C. W. Tsang, N. J. D. Graham, D. H. Lin, J. T. Sun, Y. H. Pan, X. Yang and X. D. Li, Sci. Total Environ., 2018, 619, 1153-1162.

13 Z. F. Liu, Y. T. Han, M. Jing and J. W. Chen, J. Soils Sediments, 2017, 17(3), 771-779.

14 X. Y. Ren, G. M. Zeng, L. Tang, J. J. Wang, J. Wan, Y. N. Liu, J. F. Yu, H. Yi, S. J. Ye and R. Deng, Sci. Total Environ., 2018, 610-611, 1154-1163.

15 B. Glomstad, D. Altin, L. Sørensen, J. Liu, B. M. Jenssen and A. M. Booth, Environ. Sci. Technol., 2016, 50(5), 2660.

16 I. V. Perminova, N. Y. Grechishcheva, D. V. Kovalevskii, A. V. Kudryavtsev, V. S. Petrosyan and D. N. Matorin, Environ. Sci. Technol., 2001, 35(19), 3841-3848.

17 C. Yang, Z. Shen, G. Yu and J. Wang, Bioresour. Technol., 2008, 99(14), 6240-6245.

18 X. Y. Ren, G. M. Zeng, L. Tang, J. J. Wang, J. Wan, J. J. Wang, Y. C. Deng, Y. N. Liu and B. Peng, Waste Manag., 2018, 72, 138-149.

19 H. Lin, X. H. Xia, S. Q. Bi, X. M. Jiang, H. T. Wang, Y. W. Zhai and W. Wen, Environ. Sci. Technol., 2018, 52(2), 644-653. 
20 D. Cai, X. Yang, S. Wang, Y. Chao, J. L. Morel and R. Qiu, J. Hazard. Mater., 2017, 324, 516-525.

21 X. H. Xia, A. H. Rabearisoa, X. M. Jiang and Z. N. Dai, Environ. Sci. Technol., 2013, 47(19), 10955-10963.

22 Y. L. Zhang, S. S. Lin, C. M. Dai, L. Shi and X. F. Zhou, Environ. Sci. Pollut. Res., 2014, 21, 5827-5835.

23 M. Xi, Y. Y. Zi, Q. G. Wang, S. Wang, G. L. Cui and F. L. Kong, Phys. Chem. Earth, 2018, 103, 35-44.

24 H. L. Chen, J. M. Zhou and B. H. Xiao, J. Soils Sediments, 2010, 10(5), 915-922.

25 H. C. Fu, W. Guo, R. Q. Wang, X. Q. Zhang, M. M. Zhang, W. Ma and J. L. Dai, Soil Sediment Contam., 2015, 24, 624638.

26 K. Kalbitz, S. Geyer and W. Geyer, Chemosphere, 2000, 40, 1305-1312.

27 Y. N. Hu, X. P. Liu, J. M. Bai, K. M. Shih, E. Y. Zeng and H. F. Cheng, Environ. Sci. Pollut. Res., 2013, 20(9), 61506159.

28 L. L. Niu, F. X. Yang, C. Xu, H. Y. Yang and W. P. Liu, Environ. Pollut., 2013, 176, 55-62.

29 L. Jiang, J. Huang, L. Liang, P. Y. Zheng and H. Yang, J. Agric. Food Chem., 2008, 56(24), 11933-11940.

30 K. Xiao, J. Y. Sun, Y. X. Shen, S. Liang, P. Liang, X. M. Wang and X. Huang, RSC Adv., 2016, 6, 24050-24059.

31 A. C. Bejarano, A. Widenfalk, A. W. Decho and G. T. Chandler, Environ. Toxicol. Chem., 2003, 22, 21002105.

32 N. H. Song, X. L. Yin, G. F. Chen and H. Yang, Chemosphere, 2007, 68, 1779-1787.

33 N. H. Song, S. Zhang, M. Hong and H. Yang, Environ. Pollut., 2010, 158, 906-912.

34 J. Lee, J. H. Park, Y. S. Shin, B. C. Lee, N. I. Chang, J. Cho and S. D. Kim, Ecotoxicol. Environ. Saf., 2009, 72, 335-343.

35 M. Chen and J. Hur, Water Res., 2015, 79, 10-25.

36 C. E. W. Steinberg, Ecology of Humic Substances in Freshwaters, Springer, 2003.

37 J. Hur, M. H. Lee, H. Song and M. A. Schlatman, Environ. Sci. Pollut. Res., 2013, 20, 4176-4187.

38 Y. F. Wang, X. Y. Zhang, X. Zhang, Q. J. Meng, F. J. Gao and Y. Zhang, Chemosphere, 2017, 180, 531-539.

39 S. Chen, Y. K. Yang, C. Q. Liu, F. Q. Dong and B. J. Liu, Chemosphere, 2015, 141, 162-168.

40 Q. Wang, Z. C. Yang, B. Chai, S. Cheng, X. H. Lu and X. F. Bai, RSC Adv., 2016, 6, 14730-14740.

41 M. Kočárek, R. Kodešová, L. Vondráčková, O. Golovko, M. Fér, A. Klement, A. Nikodem, O. Jakšík and R. Grabic, Environ. Pollut., 2016, 218, 563-573.

42 R. Bi, Q. Lu, T. Yuan, S. G. Zhou, Y. Yuan and Y. F. Cai, J. Environ. Sci., 2013, 25(10), 2093-2101.

43 A. O. Badejo, J. Gal, S. M. Hyun, H. I. Yi and K. H. Shin, Quatern. Int., 2014, 344(4), 211-223.

44 Y. Zhuang, R. Y. Li, H. Yang, D. L. Chen, Z. Y. Chen, B. B. Gao and B. He, Remote Sens., 2018, 10, 390.

45 J. K. Gao, J. L. Lv, H. M. Wu, Y. C. Dai and M. Nasir, Chemosphere, 2018, 193, 1027-1035.

46 D. Bannister, M. Herzog, H. F. Graf, J. S. Hosking and C. A. Short, J. Clim., 2017, 30(17), 6701-6722.
47 T. Inamura, Y. Mukai, A. Maruyama, S. Ikenaga, G. Li, X. M. Bu, Y. H. Xiang, D. Qin and T. Amano, Plant Soil, 2009, 315, 195-209.

48 X. L. Xu, L. Wang, H. Y. Cai, L. Y. Wang, L. Liu and H. Z. Wang, Food Secur., 2017, 9, 485-495.

49 H. Ma, J. Zhang, L. Y. Tong and J. X. Yang, Environ. Sci.: Processes Impacts, 2015, 17(8), 1455-1461.

50 L. A. Iturri, R. Funk, M. Leue, M. Sommer and D. E. Buschiazzo, Aeolian Res., 2017, 28, 39-49.

51 A. O. Barakat, A. Mostafa, T. L. Wade, S. T. Sweet and N. B. El Sayed, Chemosphere, 2013, 93(3), 545-554.

52 H. A. N. Abdulla, E. C. Minor, R. F. Dias and P. G. Hatcher, Geochim. Cosmochim. Acta, 2013, 118(10), 231-246.

53 F. C. Wu, R. D. Evans and P. J. Dillon, Anal. Chim. Acta, 2002, 464, 47-55.

54 Y. Yamashita and E. Tanoue, Mar. Chem., 2003, 82, 255271.

55 J. Lehmann and M. Kleber, Nature, 2015, 528(7580), 60-68.

56 R. Kalathoor, J. Botterweck, A. Schäffer, B. Schmidt and J. Schwarzbauer, J. Soils Sediments, 2015, 15, 659-670.

57 M. Li, Y. G. Chen, Y. L. Su, R. Wan and X. Zheng, RSC Adv., 2016, 6(18), 14993-15001.

58 T. Ohno and C. S. Cronan, Int. J. Environ. Anal. Chem., 1997, 66, 119-136.

59 J. Labanowski and G. Feuillade, Water Res., 2011, 45, 315327.

60 E. I. Karavanova, Eurasian Soil Sci., 2013, 46, 833-844.

61 M. Kitis, T. Karanfil, A. Wigton and J. E. Kilduff, Water Res., 2002, 36, 3834-3848.

62 L. F. Han, K. Sun, J. Jin, X. Wei, X. H. Xia, F. C. Wu, B. Gao and B. S. Xing, Environ. Sci. Technol., 2014, 48(19), 1122711234.

63 D. Zhang, B. Pan, L. C. Robert and B. S. Xing, Environ. Pollut., 2015, 196, 292-299.

64 C. Panagiotopoulos, D. J. Repeta, L. Mathieu, J. F. Rontani and R. Sempéré, Mar. Chem., 2013, 154(5), 34-45.

65 L. Hahn, M. M. Lubtow, T. Lorson, F. Schmitt, A. AppeltMenzel, R. Schobert and R. Luxenhofer, Biomacromolecules, 2018, 19(7), 3119-3128.

66 S. Xue, Y. Wen, X. J. Hui, L. N. Zhang, Z. H. Zhang, J. Wang and Y. Zhang, J. Environ. Sci., 2015, 27, 168-178.

67 D. N. Chang, W. D. Cao, J. S. Bai, S. J. Gao, X. C. Wang, N. H. Zeng and S. Katsuyoshi, Spectrosc. Spectral Anal., 2017, 37(1), 221-226.

68 N. H. Song, L. Chen and H. Yang, Geoderma, 2008, 146, 344352.

69 R. Rasool, S. S. Kukal and G. S. Hira, Soil Tillage Res., 2008, 101, 31-36.

70 H. L. Chen, J. M. Zhou and B. H. Xiao, J. Soils Sediments, 2010, 10, 915-922.

71 S. H. Wu, H. J. He, X. Inthapanya, C. P. Yang, L. Lu, G. M. Zeng and Z. F. Han, Environ. Sci. Pollut. Res., 2017, 24(20), 16560-16577.

72 M. Xi, Y. Y. Zi, Q. G. Wang, S. Wang, G. L. Cui and F. L. Kong, Phys. Chem. Earth, 2018, 103, 35-44.

73 E. A. Kim, H. V. M. Nguyen, H. S. Oh, J. Hur and J. H. Choi, Environ. Sci. Pollut. Res., 2016, 23, 5203-5213. 
74 J. B. Fellman, E. Hood and R. G. M. Spencer, Limnol. Oceanogr., 2010, 55, 2452-2462.

75 M. Heinz, D. Graeber, D. Zak, E. Zwirnmann, J. Gelbrecht and M. T. Pusch, Environ. Sci. Technol., 2015, 49, 2081-2090.

76 J. A. Leenheer and J. P. Croué, Environ. Sci. Technol., 2003, 37, 18A-26A.

77 E. C. Minor, M. M. Swenson, B. M. Mattson and A. R. Oyler, Environ. Sci.: Processes Impacts, 2014, 16, 2064-2079.

78 E. M. Perdue and J. F. Koprivnjak, Estuarine, Coastal Shelf Sci., 2007, 73, 65-72.

79 A. Huguet, L. Vacher, S. Relexans, S. Saubusse, J. M. Froidefond and E. Parlanti, Org. Geochem., 2009, 40, 706-719.

80 D. N. Kothawala, C. A. Stedmon, R. A. Müller, G. A. Weyhenmeyer, S. J. Köhler and L. J. Tranvik, Glob. Change Biol., 2014, 20, 1101-1114.

81 N. M. Mazrui, S. Jonsson, S. Thota, J. Zhao and R. P. Mason, Geochim. Cosmochim. Acta, 2016, 194, 153-162.

82 N. Mladenov, Y. Zheng, B. Simone, T. M. Bilinski, D. M. McKnight, D. Nemergut, K. A. Radloff, M. M. Rahamn and K. M. Ahmed, Environ. Sci. Technol., 2015, 49, 10815-10824.

83 T. Jiang, J. Kaal, J. Liang, Y. L. Zhang, S. Q. Wei, D. Y. Wang and N. W. Green, Sci. Total Environ., 2017, 603, 461-471.

84 C. Chen, J. J. Dynes, J. Wang and D. L. Sparks, Environ. Sci. Technol., 2014, 48(23), 13751-13759.

85 B. Pan, S. Ghosh and B. S. Xing, Environ. Sci. Technol., 2007, 41, 6472-6478.

86 Y. Y. Li, C. M. Xu, K. H. Chung and Q. Shi, Energy Fuels, 2014, 29, 2923-2930.

87 D. F. Ma, B. Peng, Y. H. Zhang, B. Y. Gao, Y. Wang, Q. Y. Yue and Q. Li, Bioresour. Technol., 2014, 165, 81-87.

88 A. Nuzzo, A. Sanchez, B. Fontaine and A. Piccolo, J. Geochem. Explor., 2013, 129, 1-5.

89 A. D. Neilen, D. W. Hawker, K. R. O'Brien and M. A. Burford, Chemosphere, 2017, 184, 969-980.

90 S. D. Li, M. L. Zhang, H. Yang, D. Q. Liu, L. Y. Yu, T. Huang and C. C. Huang, Spectrosc. Spectral Anal., 2017, 37, 11831188.

91 P. Sharma, Y. Laor, M. Raviv, S. Medina, I. Saadi, A. Krasnovsky, M. Vager, G. J. Levy, A. Bar-Tal and M. Borisover, Geoderma, 2017, 305, 197-207.

92 W. Chen, P. Westerhoff, J. A. Leenheer and K. Booksh, Environ. Sci. Technol., 2003, 37(24), 5701-5710.

93 J. H. Choi, Y. G. Kim, Y. K. Lee, S. P. Pack, J. Y. Jung and K. S. Jang, Biotechnol. Bioprocess Eng., 2017, 22(5), 637-646.

94 I. V. Kemkin and R. A. Kemkina, Dokl. Earth Sci., 2014, 455, 475-480.

95 N. A. Mikhailova, V. S. Arzhanova and S. A. Apollonova, Eurasian Soil Sci., 2004, 37, 500-505.

96 T. N. Lutsenko, V. S. Arzhanova and S. Y. Bratskaya, Eurasian Soil Sci., 2014, 47, 581-590.

97 Z. R. Tang, C. H. Huang, W. B. Tan, X. S. He, H. Zhang, D. Li and B. D. Xi, Chin. J. Anal. Chem., 2018, 46, 422-430.

98 P. Boguta, P. M. Pieczywek and Z. Sokołowska, Sensors, 2016, 16, 1760.

99 W. He and J. Hur, Water Res., 2015, 83, 217-226.
100 K. M. G. Mostofa, F. C. Wu, C. Q. Liu, W. L. Fang, J. Yuan, W. L. Ying, L. Wen and M. Yi, Limnology, 2010, 11, 217-231.

101 H. J. Lei, Y. P. Han and X. Liu, Spectrosc. Spectral Anal., 2015, 35, 1926-1932.

102 Y. L. Zhang, S. H. Yao, J. D. Mao, D. C. Olk, X. Y. Cao and B. Zhang, Soil Biol. Biochem., 2015, 85, 137-144.

103 H. W. Pan, H. B. Yu, Y. H. Song, L. Zhu, R. X. Liu and E. D. Du, Environ. Sci. Pollut. Res., 2017, 24, 6563-6571.

104 W. Wu, H. J. Sheng, C. G. Gu, Y. Song, S. Willbold, Y. Qiao, G. X. Liu, W. Zhao, Y. Wang, X. Jiang and F. Wang, Sci. Total Environ., 2018, 631, 1495-1503.

105 S. E. M. Dvorski, M. Gonsior, N. Hertkorn, J. Uhl, H. Muller, C. Griebler and P. Schmitt-Kopplin, Environ. Sci. Technol., 2016, 50, 5536-5546.

106 H. B. Peng, B. Pan, M. Wu, R. Liu, D. Zhang, D. Wu and B. S. Xing, J. Hazard. Mater., 2012, 211-212, 342-348.

107 B. Z. Zhao, J. B. Zhang, Y. Y. Yu, D. L. Karlen and X. Y. Hao, Environ. Sci. Pollut. Res., 2016, 23(17), 17581-17591.

108 M. Yamamoto, A. Nishida, K. Otsuka, T. Komai and M. Fukushima, Bioresour. Technol., 2010, 101, 4456-4460.

109 B. Wang, X. Shen, S. Chen, Y. C. Bai, G. Yang, J. P. Zhu, J. C. Shu and Z. Y. Xue, Ecol. Indic., 2018, 93, 998-1004.

110 M. J. M. Rusan and H. I. Malkawi, Desalin. Water Treat., 2016, 57(57), 27945-27953.

111 T. Ahmed, K. Ohta, O. Nagafuchi and M. Maruo, Environ. Toxicol. Chem., 2012, 31, 2201-2209.

112 S. Frankki, Y. Persson, M. Tysklind and U. Skyllberg, Environ. Sci. Technol., 2006, 40, 6668-6673.

113 J. H. Writer, J. N. Ryan and L. B. Barber, Environ. Sci. Technol., 2011, 45, 7275-7283.

114 S. Xue, Q. L. Zhao, L. L. Wei, Y. T. Song and M. Tie, Environ. Monit. Assess., 2013, 185, 4591-4603.

115 H. Y. Sun, X. Shi, J. D. Mao and D. Q. Zhu, Environ. Toxicol. Chem., 2010, 29, 1934-1942.

116 A. Muscolo, M. Sidari and S. Nardi, J. Geochem. Explor., 2013, 129, 57-63.

117 O. E. Trubetskaya, O. A. Trubetskoj, G. Voyard and C. Richard, J. Geochem. Explor., 2013, 132, 84-89.

118 M. Q. Yan, D. Dryer, G. V. Korshin and M. F. Benedetti, Water Res., 2013, 47, 588-596.

119 C. H. Fan, Y. C. Zhang and J. H. Wang, Spectrosc. Spectral Anal., 2015, 35, 3146-3150.

120 J. H. Writer, J. N. Ryan and L. B. Barber, Environ. Sci. Technol., 2011, 45, 7275-7283.

121 M. X. Wei, B. Wang, S. Chen, Y. C. Bai, F. Q. Dong, J. P. Zhu, M. Li and J. Wei, Spectrosc. Spectral Anal., 2017, 37(9), 28612868.

122 J. K. Gao, J. L. Lv, H. M. Wu, Y. C. Dai and M. Nasir, Chemosphere, 2018, 193, 1027-1035.

123 E. E. Lavonen, D. N. Kothawala, L. J. Tranvik, M. Gonsior, P. Schmitt-Kopplin and S. J. Kohler, Water Res., 2015, 85, 286-294.

124 B. N. Bhadra and S. H. Jhung, J. Hazard. Mater., 2017, 340, 179-188.

125 Q. Q. Wu, Q. Yang, W. J. Zhou and L. Z. Zhu, J. Soils Sediments, 2015, 15, 2210-2219. 
126 N. Liang, D. Zhang, C. X. Wei, H. Li, S. Ghosh, Y. B. Cao and B. L. Guo, Environ. Eng. Sci., 2015, 32, 703-712.

127 D. M. Wu, Y. H. Yun, L. Jiang and C. Y. Wu, Sci. Total Environ., 2018, 616, 1449-1456.

128 S. Xue, Q. L. Zhao, L. L. Wei, Y. T. Song and M. Tie, Environ. Monit. Assess., 2013, 185, 4591-4603.

129 T. Polubesova and B. Chefetz, Crit. Rev. Environ. Sci. Technol., 2014, 44, 223-254.

130 K. L. Yang, Y. L. Zhang, Y. P. Dong, Z. Nie and W. Li, Environ. Eng. Sci., 2017, 34, 675-686.

131 A. Y. Zherebker, I. V. Perminova, A. I. Konstantinov, A. B. Volikov, Y. I. Kostyukevich, A. S. Kononikhin and E. N. Nikolaev, J. Anal. Chem., 2016, 71, 372-378.

132 M. Markiewicz, C. Jungnickel and H. P. H. Arp, Environ. Sci. Technol., 2013, 47, 6951-6958.

133 H. B. Wang and Y. J. Zhang, J. Environ. Sci. Health, Part A: Toxic/Hazard. Subst. Environ. Eng., 2014, 49(1), 78-84.

134 H. Y. Fu, C. H. Wei, X. L. Qu, H. Li and D. Q. Zhu, Environ. Pollut., 2018, 232, 402-410.

135 J. Jin, K. Sun, Z. Y. Wang, Y. Yang, L. F. Han and B. S. Xing, Environ. Sci. Technol., 2017, 51(5), 2635-2642.

136 C. P. Yang, H. Qian, X. Li, Y. Cheng, H. J. He, G. M. Zeng and J. Y. Xi, Trends Biotechnol., 2018, 36(7), 673-685.

137 Y. Cheng, H. J. He, C. P. Yang, G. M. Zeng, X. Li, H. Chen and G. L. Yu, Biotechnol. Adv., 2016, 34(6), 1091-1102.

138 X. Y. Guo, X. L. Wang, X. Z. Zhou, X. Z. Kong, S. Tao and B. S. Xing, Environ. Sci. Technol., 2012, 46(13), 7252-7259.

139 Y. L. Li, W. He, W. X. Liu, X. Z. Kong, B. Yang, C. Yang and F. L. Xu, Environ. Pollut., 2015, 206, 461-468.
140 M. Uchimiya and D. I. Bannon, J. Agric. Food Chem., 2013, 61, 7679-7688.

141 K. L. Chen, L. C. Liu and W. R. Chen, Environ. Pollut., 2017, 231, 1163-1171.

142 L. Ming, L. H. Li, Y. X. Zhang, W. Y. Lin, G. Z. Wang, S. Zhang and P. Guo, Chem. Ecol., 2014, 30, 76-86.

143 C. Y. Yuan, Y. P. Chin and L. K. Weavers, Water Res., 2018, 132, 52-60.

144 M. L. Pace, I. Reche, J. J. Cole, A. Fernandez-Barbero, I. P. Mazuecos and Y. T. Prairie, Biogeochemistry, 2012, 108(1-3), 109-118.

145 D. Gondar, R. Lopez, J. Antelo, S. Fiol and F. Arce, J. Hazard. Mater., 2012, 235-236(2), 218-223.

146 B. Pan, M. Y. Qiu, M. Wu, D. Zhang, H. B. Peng, D. Wu and B. S. Xing, Environ. Pollut., 2012, 161, 76-82.

147 D. Durce, N. Maes, C. Bruggeman and L. Van Ravestyn, J. Contam. Hydrol., 2016, 185, 14-27.

148 A. H. M. A. Sadmani, R. C. Andrews and D. M. Bagley, Chemosphere, 2014, 117, 170-177.

149 Y. L. Wang, C. M. Yang, L. M. Zou and H. Z. Cui, Appl. Spectrosc., 2015, 69, 623-634.

150 Y. Kim and D. Lee, J. Hazard. Mater., 2002, 91(1), 113-127.

151 W. Wu, H. J. Sheng, C. G. Gu, Y. Song, S. Willbold, Y. Qiao, G. X. Liu, W. Zhao, Y. Wang, X. Jiang and F. Wang, Sci. Total Environ., 2018, 631, 1495-1503.

152 Y. H. Wu, Y. B. Si, D. M. Zhou and J. Gao, Chemosphere, 2015, 119, 690-696.

153 Y. F. Wang, X. Y. Zhang, X. Zhang, Q. J. Meng, F. J. Gao and Y. Zhang, Chemosphere, 2017, 180, 531-539. 